CLINICAL ETHICS

\title{
Gaps, conflicts, and consensus in the ethics statements of professional associations, medical groups, and health plans
}

\author{
N D Berkman, M K Wynia, L R Churchill
}

J Med Ethics 2004;30:395-401. doi: 10.1136/jme.2002.000729

See end of article for authors' affiliations

....................

Correspondence to: Dr M K Wynia, The Institute for Ethics at the American Medical Association, 515 North State Street, Chicago, IL 60610, USA; matthew_wynia@ ama-assn.org

Received 23 May 2002 Accepted for publication 29 November 2002

\begin{abstract}
Background: Patients today interact with physicians, physician groups, and health plans, each of which may follow distinct ethical guidelines.

Method: We systematically compared physician codes of ethics with ethics policies at physician group practices and health plans, using the 1998-99 policies of 38 organisations-18 medical associations (associations), nine physician group practices (groups), and 12 health plans (plans)-selected using random and stratified purposive sampling. A clinician and a social scientist independently abstracted each document, using a 397-item health care ethics taxonomy; a reconciled abstraction form was used for analysis. This study focuses on ethics policies regarding professional obligation towards patients, resource allocation, and care for the vulnerable in society.

Results: A majority in all three groups mention "fiduciary obligations" of one sort or another, but associations generally address physician/patient relations but not health plan obligations, while plans rarely endorse physicians' obligations of advocacy, beneficence, and non-maleficence. Except for occasional mentions of cost effectiveness or efficiency, ethical considerations in resource allocation rarely arise in the ethics policies of all three organisational types. Very few associations, groups, or plans specifically endorse obligations to vulnerable populations.

Conclusions: With some important exceptions, we found that the ethics policies of associations, groups, and plans are narrowly focused and often ignore important ethical concerns for society, such as resource allocation and care for vulnerable populations. More collaborative work is needed to build integrated sets of ethical standards that address the aims and responsibilities of the major stakeholders in health care delivery.
\end{abstract}

S ince Hippocrates and before, physicians have created norms of moral conduct to define their roles and delineate their responsibilities. ${ }^{1-3}$ Medical codes and oaths have sought to address the special issues that physicians encounter in dealing with the sick and vulnerable. Since the adoption of the code of medical ethics by the American Medical Association (AMA) in 1847, public affirmation, or "profession," of codes of ethics has been used explicitly to guide physician conduct and thinking and to engender public trust and patient confidence. ${ }^{14}$ Yet recent changes in the financing and organisation of health care present challenges to traditional physician ethics. ${ }^{5-10}$ The advent of managed care has made lines of responsibility for patient welfare more complex and transformed the traditionally dyadic patient/physician relationship into a multifaceted set of interactions between patients, practitioners, insurers, and others. ${ }^{11}{ }^{12}$ In particular, increasing numbers of physicians practise in large groups and work as employees of, or under contracts with, health plans. ${ }^{13}{ }^{14}$ Today, the policies of physician groups and health plans often directly affect the practice of medicine and patient/physician relations.

With more parties involved in health care, it has become important to clarify the ethical responsibilities of each party. ${ }^{15-17}$ Since norms in medicine, public health, business, and other aspects of health care delivery may differ, it is possible that expectations regarding ethical actions for each party may be in conflict. ${ }^{18-21}$ On the other hand, shared expectations may also exist and there may be areas where the expectations of parties are different, but complementary to each other. ${ }^{22}{ }^{23}$ Whether ethical norms are in agreement or in conflict is a question of substantial importance, since norms help to shape not only individual actions and corporate policies but questions of legal accountability as well. ${ }^{14}$ The recent national debate in the US over accountability in a "patients' bill of rights" is vivid testimony to the importance of shared expectations in health care.

Though physicians often lament that managed care organisations do not understand or foster physicians' professional ethics, to date no systematic analysis has been made of whether the professional ethics of physicians, as expressed through the codes of ethics of medical associations, are endorsed, rejected, or ignored in the written ethics policies of group practices and health plans. We performed a structured review of written ethics policies from these three types of organisations. We compared the policies for gaps, conflicts, consensus, and complementarity with regard to three core professional obligations: (1) toward patients, (2) for resource allocation, and (3) to care for the vulnerable in society.

\section{METHODS}

\section{Sample selection}

In 1998 we conducted a confidential mail survey of 204 organisations of three types: 70 physician professional associations (associations), including the AMA and the 69 physician specialty societies and state medical associations that had reported in an earlier survey that they had independently produced ethics policies (often in addition to having adopted AMA ethics policies); 59 physician group practices (groups), randomly selected from the Medical Group Management Association Directory; and 75 managed health care organisations (plans), randomly selected from the American Association of Health Plans Directory. Both random samples were drawn using a random number generator to select pages from the directories from which to sample. 
Of 204 organisations queried, 89 (44\%) were eligible for inclusion in the study. Eligible organisations were those that responded to our request for information, had ethics related materials, and provided copies of all of these materials. Based on resource limitations, we could not review the materials from all eligible organisations. We therefore selected 39 organisations for inclusion as follows (table 1). Eighteen associations (including the AMA) were selected by the research team, using a stratified purposive sample to represent a cross-section of disciplines and a national geographic distribution of state associations. Nine groups were purposively selected to represent a mixture of organisations by size (ranging from less than 50 to several hundred physicians) and geographic location. All 12 eligible plans were included. All selections for inclusion were made prior to data analysis.

\section{Survey data}

We collected information on each organisation through a short survey. We asked a senior manager to describe the organisation's characteristics and to list all of the organisation's documents with ethics related content. It was left to the organisation to determine all that it considered to be ethics related documents; a prompting list suggested codes of ethics, patients' rights statements, policy statements, and several other types of documents as possible sources of these materials. Each organisation was then requested to provide the research team with copies of all the listed documents. Since these materials might include sensitive materials, such as proprietary contract language, organisations were assured confidentiality and that our analysis and reporting on their materials would occur only in aggregate with other organisations of similar type.

\section{Data abstraction}

In a first stage of the project, 13 organisations' materials, representing a cross section of the organisational types included in the study, were used to create a comprehensive taxonomy of the potential contents of organisations' ethics documents. $^{24}$ A nine member expert panel, including physicians, medical ethicists, health services researchers, and managed care experts, developed the taxonomy in an iterative process using their expert knowledge of the field and by considering the materials reviewed-both in terms of topic areas mentioned and the specificity of the discussion.

The resulting taxonomy includes 397 separate items that might be addressed in a set of ethics materials. Topics are included in the taxonomy both as stand alone items and in a hierarchical fashion, capturing general issues-for example, beneficence, non-maleficence, charity, etc as well as greater levels of detail-for example, beneficence: providers toward patients. The abstraction instrument that was used for data collection includes all 397 items contained in the taxonomy, grouped into 17 general topic areas (table 2). It was designed to promote precision in data abstraction and to facilitate converting the prose contained in a variety of ethics related documents into data items, which can be counted and sorted into topic areas. This method allowed us to pull together a large amount of textual material into meaningful and parsimonious units of analysis to usefully compare materials across organisational types. ${ }^{25}$ (The complete taxonomy and data abstraction tool is available at www.ama-assn.org/go/ ethicsinstitute.)

Data abstraction was carried out by a team of researchers from the Research Triangle Institute and University of North Carolina who were experienced in conducting structured reviews. ${ }^{26}$ Reviewers matched each item contained in the materials they reviewed to one of the 397 taxonomy categories. They were permitted to create new taxonomy categories if necessary but this happened very rarely and did not affect the analyses presented here. Each code was reviewed twice, by a clinician and a social scientist, with a final reconciled abstraction provided by each pair of reviewers. If an organisation specifically mentioned another organisation's materials as binding-for example, state associations often referred to the AMA's Principles of Medical Ethics, then these secondary materials were considered to be part of the first organisation's policies. On average, abstraction of an organisation's documents took each reviewer five hours to complete.

\section{Data analysis and reporting}

This study focuses on three major topic areas that are central to professional ethics and health care relationships, using 67 of the 397 items in the taxonomy. First, 32 items addressing beneficence, advocacy, fiduciary obligations, and non-maleficence formed one category ("Professional obligations to patients"). Next, 19 items addressing resource allocations/ coverage decisions formed a second category ("Resource allocation processes"). Finally, 16 items addressing care for various vulnerable populations formed the third category ("Care for the vulnerable"). For each category, we report counts of how often organisations of each type addressed each individual item included within the category. For this report, we also selected a few specific organisational policy statements to provide illustrative examples. Finally, while our sample size was relatively modest, we conducted $\chi^{2}$ tests to assess whether certain items were preferentially addressed by associations compared to groups or plans.

\section{RESULTS}

\section{Professional obligations to patients}

Organisational policies might address professional obligations to patients in terms of beneficence, fiduciary obligations, non-maleficence, or advocacy. Beneficence is one of the oldest and most basic obligations in health care. ${ }^{27}{ }^{28}$ It refers broadly to the responsibility to seek the wellbeing of patients and to place patients' good above other aims or goals. For example, one association policy addressed beneficence by stating: "physicians shall embrace patient welfare as their

Table 1 Organisations sampled, sampling strategies, response rates, and inclusion rates

\begin{tabular}{|c|c|c|c|c|}
\hline Organisation Type & Sampling approach & $\begin{array}{l}\text { Partial sets of } \\
\text { documents received }\end{array}$ & $\begin{array}{l}\text { Complete sets of } \\
\text { documents received }\end{array}$ & Number reviewed \\
\hline $\begin{array}{l}\text { Physician professional } \\
\text { associations }\end{array}$ & $\begin{array}{l}\text { All } 70 \text { societies with independent ethics } \\
\text { policies, }{ }^{*} \text { including the AMA }\end{array}$ & $9(13 \%)$ & $57(84 \%)$ & 18 \\
\hline Physician group practices & $\begin{array}{l}59 \text { groups, selected at random from Medical } \\
\text { Group Management Association Directory }\end{array}$ & $10(17 \%)$ & $19(32 \%)$ & 9 \\
\hline Health plans & $\begin{array}{l}75 \text { plans, selected at random from American } \\
\text { Association of Health Plans Directory }\end{array}$ & $11(15 \%)$ & $12(16 \%)$ & 12 \\
\hline
\end{tabular}

*Physician professional associations that require adherence to the Code of Medical Ethics or Principles of Medical Ethics of the American Medical Association (AMA), but which have no other ethics policies, were not eligible for inclusion. 
Table 2 Major taxonomy categories and the number of items from the abstraction form that comprise each category

\begin{tabular}{ll}
\hline Taxonomy categories & $\begin{array}{l}\text { Number of items in the } \\
\text { category }\end{array}$ \\
\hline Professional obligations towards patients* & 34 \\
Resource allocation/coverage decisions & 25 \\
Vulnerable populations* & 15 \\
Patient rights/autonomy & 30 \\
Privacy and confidentiality & 14 \\
Conflicts of interest & 21 \\
End of life care & 19 \\
Access to care & 12 \\
Public health & 12 \\
Patient responsibilities & 7 \\
Genetics & 6 \\
Contributions to a shared future & 5 \\
Ethics code orientation and audience/policy enforcement & $10^{* *}$ \\
\hline \multirow{2}{*}{ *Category that is a focus of this report. } & \\
${ }^{* *}$ Includes 3 items obtained from the organisational survey (see Methods). &
\end{tabular}

primary professional responsibility". Public statements of such obligations are intended to foster patient trust in health care practitioners and organisations. Yet there were significant differences among organisational types regarding the inclusion of a principle of beneficence and to whom it applies (table 3). While 16 of 18 associations ( $89 \%$ ) had a statement of some kind concerning beneficence either generally or in terms of more specific relationships, this was true of only two out of nine groups (22\%) and one out of 12 plans ( $8 \%)$. More specifically, most association policies discussed beneficence on the part of physicians toward individual patients $(72 \%)$, while only $11 \%$ of groups addressed this and none of the plans did so. A small percentage of associations (28\%) and groups $(11 \%)$, and no plans, addressed beneficence as part of a practitioner's duty toward a "covered population". No organisations discussed beneficence in terms of health plan obligations toward individual patients. Only one plan, and no other organisations, addressed plan obligations of beneficence toward covered populations.

The table does not include a few items that none of the organisations addressed in their ethics materials. These were: beneficence of providers towards trainees; beneficence of health plans toward patients; and non-maleficence towards organisations and towards colleagues.

Another traditional duty of physicians is non-maleficence, or the duty to avoid, minimise, or protect from, harm. ${ }^{28}$ While non-maleficence has long had currency in the professional ethics literature, its importance in health policy might be rising. For instance, one declared motivation for a "patients' bill of rights" has been to avoid potential harms arising from health plan decisions. Associations were significantly more likely to address non-maleficence, with $50 \%$ of associations mentioning it, compared to no groups or plans.

Some language regarding "fiduciary obligations" was included in the materials of most of the three types of organisations; but the nature of, and parties to, the relationships addressed by this language varied. Only a small percentage of all organisational types specified a fiduciary obligation of individual physicians toward their patients, while one group and one plan mentioned an organisational fiduciary obligation toward "enrolees". Associations were significantly more likely than groups or plans to address obligations of disclosure of financial incentives to patients. Associations were also more likely than plans to address obligations of honesty/truth telling/veracity and to address issues arising from the termination of practitioner/patient relationships. On the other hand, two plans addressed organisational responsibilities of balancing obligations to enrolees with obligations to other stakeholders, which no associations mentioned. Use of a related term, "advocacy", illustrates this division between organisational types as well. Associations were significantly more likely to address advocacy compared to groups or plans, and they tended to discuss advocacy of physicians for their patients. On the other hand, two plans included language concerning the plan's advocacy for all enrolees-an obligation that no association or group noted.

\section{Resource allocation/coverage decision making processes}

In this category we looked for inclusion of broader concepts, such as equality, stewardship, justice, rationing, and more specific activities, such as coverage of experimental treatments, necessity determinations, and use of evidence based medicine (table 4). Across all organisational types, a majority addressed resource allocation issues in some way, but most commonly it was only through mention of cost effectiveness or efficiency. Justice, which may be the most widely used ethical principle in discussions of allocation and coverage decisions, ${ }^{29}$ was more likely to be included in the ethics policies of associations, compared to groups or plans. But the term "stewardship", which is increasingly used in the religious and ethics literature to describe an obligation to allocate shared resources carefully, ${ }^{30-34}$ was used in only a few of the ethics policies we reviewed. Rationing was not mentioned in any group or plan materials and in only a minority of association materials.

\section{Care for vulnerable populations}

Care for the indigent, the uninsured, and other vulnerable populations enjoys wide endorsement among health care professionals, and is held as a central commitment by many. ${ }^{85-37}$ For example, the AMA recently revised its Principles of Medical Ethics to state: "A physician shall support access to medical care for all people". ${ }^{38}$

In this category, we included terms that captured care for the vulnerable as a general virtue, such as "charity", "advocacy for the uninsured", and "Good Samaritan" policies, and general obligations to vulnerable groups, searching for discussions of "abuse and neglect", "health care for special populations," and related issues (table 5). We also searched for mention of specific vulnerable populations, including "the uninsured", "the poor", "the homeless", "the disabled", "prisoners", and "undocumented workers". Across all 16 items examined, few organisations addressed care for vulnerable populations in their ethics materials. Associations were significantly more likely than plans to 
Table 3 Professional obligations towards patients, as addressed in ethics policies. Whether and how three different types of organisations mention some core professional obligations towards patients in their written ethics policies and statements

\begin{tabular}{|c|c|c|c|}
\hline \multirow[b]{2}{*}{ Topic } & \multicolumn{3}{|c|}{ Organisational type } \\
\hline & $\begin{array}{l}\text { Physician } \\
\text { professional } \\
\text { associations } \\
(\mathrm{N}=18) \text { n (\%) }\end{array}$ & $\begin{array}{l}\text { Physician group } \\
\text { practices } \\
(\mathrm{N}=9) \text { n (\%) }\end{array}$ & $\begin{array}{l}\text { Managed } \\
\text { care plans } \\
(\mathrm{N}=12) \mathrm{n}(\%)\end{array}$ \\
\hline Beneficence (any mention): & $16(89)$ & $2(22)^{* *}$ & $1(8)^{* *}$ \\
\hline General mention & $4(22)$ & $0(0)$ & $0(0)^{*}$ \\
\hline Providers towards patients & $13(72)$ & $1(11)^{* *}$ & $0(0)^{* *}$ \\
\hline Providers toward population & $5(28)$ & $1(11)$ & $0(0)^{* *}$ \\
\hline Health plan toward populations & $0(0)$ & $0(0)$ & $1(8)$ \\
\hline Health plan toward employees & $0(0)$ & $1(11)$ & $0(0)$ \\
\hline $\begin{array}{l}\text { Obligation to place the wellbeing of patients } \\
\text { above self interest }\end{array}$ & $7(39)$ & $0(0)^{* *}$ & $0(0)^{* *}$ \\
\hline Non-maleficence (any mention): & $9(50)$ & $0(0)^{* *}$ & $0(0)^{* *}$ \\
\hline General mention & $3(17)$ & $0(0)$ & $0(0)$ \\
\hline Toward patients & $4(22)$ & $0(0)$ & $0(0)^{*}$ \\
\hline Toward trainees & $2(11)$ & $0(0)$ & $0(0)$ \\
\hline $\begin{array}{l}\text { Professional responsibility to refrain from } \\
\text { harming patients }\end{array}$ & $4(22)$ & $0(0)$ & $0(0)^{*}$ \\
\hline Fiduciary obligations/relationships (any mention): & $15(83)$ & $6(67)$ & $10(83)$ \\
\hline General mention & $1(6)$ & $0(0)$ & $0(0)$ \\
\hline Compensation/financial incentives & $9(50)$ & $2(22)$ & $3(25)$ \\
\hline Provider to patient & $3(17)$ & $1(11)$ & $1(8)$ \\
\hline Provider to covered population & $1(6)$ & $0(0)$ & $0(0)$ \\
\hline Health plan to enrolees/members & $0(0)$ & $1(11)$ & $1(8)$ \\
\hline Financial incentives: disclosure to public & $2(11)$ & $0(0)$ & $0(0)$ \\
\hline Financial incentives: disclosure to patients & $8(44)$ & $0(0)^{* *}$ & $2(17)^{*}$ \\
\hline Financial incentives: as a threat to fiduciary duties & $2(11)$ & $1(11)$ & $3(25)$ \\
\hline Honesty/truth telling/veracity & $11(61)$ & $5(56)$ & $2(17)^{\star *}$ \\
\hline Termination of provider/patient relationship & $6(33)$ & $1(11)$ & $1(8)^{*}$ \\
\hline Trust & $6(33)$ & $0(0)^{*}$ & $3(25)$ \\
\hline $\begin{array}{l}\text { Organisational responsibility: to balance fiduciary } \\
\text { obligations to enrolees in health plans with } \\
\text { obligations to stock holders }\end{array}$ & $0(0)$ & $0(0)$ & $2(17)^{*}$ \\
\hline Advocacy (any mention): & $12(67)$ & $1(11)^{* *}$ & $3(25)^{\star *}$ \\
\hline General mention & $4(22)$ & $0(0)$ & $1(8)$ \\
\hline Provider for patients & $10(56)$ & $1(11)^{*}$ & $0(0)^{* *}$ \\
\hline Provider for covered populations & $2(11)$ & $0(0)$ & $0(0)$ \\
\hline
\end{tabular}

Table 4 Resource allocation/coverage decision making, as addressed in ethics policies. Whether and how three different types of organisations mention issues of resource allocation and coverage decision making processes in their written ethics policies and statements

\begin{tabular}{|c|c|c|c|}
\hline \multirow[b]{2}{*}{ Topic } & \multicolumn{3}{|c|}{ Organisational type } \\
\hline & $\begin{array}{l}\text { Physician } \\
\text { professional } \\
\text { associations } \\
\mathrm{N}=18 \mathrm{n}(\%)\end{array}$ & $\begin{array}{l}\text { Physician group } \\
\text { practices } \\
\mathrm{N}=9 \text { n (\%) }\end{array}$ & $\begin{array}{l}\text { Managed care } \\
\text { plans } \\
N=12 \text { n (\%) }\end{array}$ \\
\hline Equality & $1(6)$ & $1(11)$ & $2(17)$ \\
\hline Equality: among segments of the population & $1(6)$ & $0(0)$ & $0(0)$ \\
\hline Equality: among patients & $0(0)$ & $1(11)$ & $1(8)$ \\
\hline Stewardship of resources & $2(11)$ & $2(22)$ & $1(8)$ \\
\hline Justice & $6(33)$ & $0(0)^{*}$ & $1(8)^{*}$ \\
\hline Rationing/triage & $3(17)$ & $0(0)$ & $0(0)$ \\
\hline Efficiency or cost effectiveness & 7 (39) & $6(67)$ & $5(42)$ \\
\hline Universal coverage & $1(6)$ & $0(0)$ & $0(0)$ \\
\hline $\begin{array}{l}\text { Resource allocation/coverage decisions (any } \\
\text { mention) }\end{array}$ & $11(61)$ & $7(78)$ & $8(67)$ \\
\hline General mention & $4(22)$ & $1(11)$ & $0(0)^{*}$ \\
\hline Benefits determinations & $0(0)$ & $0(0)$ & $0(0)$ \\
\hline Methods for distribution & $4(22)$ & $0(0)$ & $0(0)^{*}$ \\
\hline Use of evidence based medicine & $1(6)$ & $0(0)$ & $0(0)$ \\
\hline Involving community in decision making & $1(6)$ & $0(0)$ & $0(0)$ \\
\hline Practice parameters/outcomes data & $4(22)$ & $1(11)$ & $1(8)$ \\
\hline Coverage of "experimental" treatments & $1(6)$ & $0(0)$ & $0(0)$ \\
\hline Necessity determinations (need/rule of rescue) & $2(11)$ & $0(0)$ & $0(0)$ \\
\hline
\end{tabular}


discuss abuse and neglect of children, but overall, mention of charity, care for the uninsured, and so on were rare.

\section{DISCUSSION}

In this study, we examined ethics documents from three types of organisations-physician professional associations, physician group practices, and managed care health plansfor their content regarding three core ethical obligations in health care: (1) professional obligations toward patients, (2) obligations with regard to resource allocation, and (3) obligations to care for the vulnerable in society. Initially, we set out to examine whether the organisations in which physicians practise have established ethics policies that are consistent with adopted codes of ethics for the profession. But our most striking finding is that two of these three core ethical obligations-obligations regarding resource allocation and obligations to care for the vulnerable in society-have received scant attention from any of the groups we studied.

Largely because so few organisations dealt with issues of care for vulnerable populations and resource allocation, it was only in relation to professional obligations to patients that we found what may be important distinctions across the three different types of organisations. For instance, while many professional associations assert physicians' obligations of beneficence, non-maleficence, and advocacy for patients, no health plans and only rare group practice policies affirm these duties. Meanwhile, a few health plans addressed their own organisational obligations of beneficence or advocacy for enrolees as a group-but no group practices or professional associations affirmed these plan level obligations. The absence of comments on each others' ethical obligations may indicate a tendency to focus only on one's own responsibilities and a respectful reticence to speak to the obligations of other actors in the system, but it might also reflect a lack of acknowledgement of the interdependent nature of health care today. Ultimately, the ethics of each party in health care should be integrated with, and preferably complementary to, the ethics of the other important actors in the system. ${ }^{15-17}$

Even more startling, given the health care system of today, is the paucity of discussion in these ethics documents about issues of resource allocation, which have increasingly preoccupied academic ethicists and policy makers for more than 20 years. ${ }^{29}{ }^{39-46}$ Although many organisations professed the importance of providing cost effective care, other resource allocation topics were either not addressed or were addressed in only a small minority of the ethics codes and policies we examined. For instance, "stewardship" and "justice" were rarely mentioned. While the general absence of "rationing" may not be surprising (after all, these are mainly public documents and the public appears reticent to address rationing in health care), the absence of mention of "necessity determinations" and "experimental treatments" among plan and group ethics materials is remarkable. Almost certainly, these organisations have policies to address these issues-that they are not mentioned in their ethics documents suggests that many do not recognise or acknowledge these issues as having important ethical content.

Distressingly few professional or care delivery organisations have ethics policies that address care for vulnerable populations in society. Though obligations to provide charity or uncompensated care and to advocate for the uninsured appear frequently in the ethics literature ${ }^{35} 37$ and in some prominent professional codes of ethics, ${ }^{47}$ these discussions have not made their way into the codes of ethics for the majority of physicians' professional associations, and they were absent from virtually all of our sample of physician group practice and health plan ethics policies and statements.

\section{Limitations}

Conclusions about morality and ethical behaviour based on an examination of ethics codes and other materials must be very cautiously drawn, if at all. First, one must recognise that the ethical attitudes and behaviours of individuals may not precisely mirror the official statements of organisations. For example, it is clear that many physicians are highly sensitive to the plight of vulnerable populations in society, regardless whether this shows up in the codes of ethics of their professional associations, group practices, or heath plans. Unfortunately, the opposite can be true as well-the high aspirations sometimes reflected in codes and policies may not be realised in practice. Second, the policies we examined may not fully reflect the actions of organisations. For example, it was noted that health plans almost certainly give more

\begin{tabular}{|c|c|c|c|}
\hline \multirow[b]{2}{*}{ Topic } & \multicolumn{3}{|l|}{ Organisational type } \\
\hline & $\begin{array}{l}\text { Physician professional } \\
\text { associations } \\
(\mathrm{N}=18) \text { n (\%) }\end{array}$ & $\begin{array}{l}\text { Physician group } \\
\text { practices } \\
(\mathrm{N}=9) \mathrm{n}(\%)\end{array}$ & $\begin{array}{l}\text { Managed } \\
\text { care plans } \\
(\mathrm{N}=12) \mathrm{n}(\%)\end{array}$ \\
\hline Obligations (any mention): & $8(44)$ & $2(22)$ & $2(17)$ \\
\hline Charity & $2(11)$ & 2 (22) & $0(0)$ \\
\hline Advocacy for the uninsured & $3(17)$ & $0(0)$ & $0(0)$ \\
\hline "Good Samaritan" policy & $3(17)$ & $0(0)$ & $0(0)$ \\
\hline Abuse and neglect & $2(11)$ & $0(0)$ & $0(0)$ \\
\hline Abuse and neglect: children & $6(33)$ & $1(11)$ & $0(0)^{*}$ \\
\hline Rural health care & $2(11)$ & $0(0)$ & $0(0)$ \\
\hline \multirow{2}{*}{\multicolumn{4}{|c|}{ Health care for special populations }} \\
\hline & & & \\
\hline General mention & $1(6)$ & $0(0)$ & $0(0)$ \\
\hline The disabled & $2(11)$ & $0(0)$ & $0(0)$ \\
\hline The uninsured & $2(11)$ & 2 (22) & $1(8)$ \\
\hline The homeless & $2(11)$ & $0(0)$ & $0(0)$ \\
\hline The poor & $4(22)$ & 2 (22) & $2(17)$ \\
\hline Prisoners & $1(6)$ & $0(0)$ & $0(0)$ \\
\hline Undocumented workers & $1(6)$ & $0(0)$ & $0(0)$ \\
\hline Children in detention & $1(6)$ & $0(0)$ & $0(0)$ \\
\hline
\end{tabular}


attention to resource allocation processes than their ethics policies indicate, whether or not the ethical content of these processes is recognised as such. Third, our analysis compares counts of mentions of items or categories-as such, it may not fully capture differences in the depth of discussion between organisations. On the other hand, where important issues were not mentioned at all this potential inability to discern the depth of discussion is moot. Finally, the materials we collected may be incomplete and these materials are certainly in constant evolution. ${ }^{38}$ Some terms, such as "stewardship", may well be increasingly prevalent, ${ }^{30-33}$ a possibility that a cross sectional study cannot confirm or deny. Another reason for incomplete ethics policies, especially among professional associations, may be the widespread acceptance of the near exhaustive AMA Code of Medical Ethics. But many organisations make no specific mention of AMA policies and most who do have adopted only the one page AMA Principles of Medical Ethics, without mention of the ethical guidelines provided by the AMA Council on Ethical and Judicial Affairs in the full Code of Medical Ethics, which spans more than 130 pages ${ }^{48}$ Among all the organisations we examined, only one state association had a policy affirming the full AMA Code of Medical Ethics.

Finally, for two reasons, we wish to draw attention to the relatively low response rate we achieved among group practices and health plans, despite appeals from a multidisciplinary group of leaders in health care ${ }^{49}$ and the promise of confidentiality. First, the low response rate increases the possibility of a response bias. Organisations willing to submit their policies for review may have materials of which they are proud, which might be relatively exemplary. This suggests that our study may overstate the completeness of ethics policies at typical organisations.

Second, and more worrisome, is that ethical standards reflect social contracts between health care organisations and the general public. Ethics codes and policies are one way to reassure the public about the good intentions of professionals and organisations, and hence they are a means of eliciting trust. ${ }^{1}$ Such trust is important for any organisation or profession; in health care it is essential. ${ }^{75}$ But ethical standards cannot perform this trust building function if they are not clearly stated and easily accessible. In this sense then, the "quality" of ethics materials may be measured both by the extent to which they address areas of public concern and by the extent to which they are publicly accessible. Seen in this light, the low response rates we saw are themselves notable study findings. Remarkably, some non-participating organisations claimed to have no ethics related materials; others declined to participate because their ethics policies were confidential, even "proprietary". Moreover, it was not unusual to find organisations' ethics materials spread across several documents with no obvious coordination among them. Thus a patient, purchaser, or clinician interested in the ethical standards of a health care organisation would have a very difficult time locating relevant materials or understanding their interconnections.

\section{CONCLUSION}

This study is the first systematic analysis of the written ethical standards of physician professional associations, physician group practices, and health plans, with the aim of identifying gaps, conflicts, and consensus. Given vocal and persistent concerns, from both physicians and the public, about how group and plan policies can affect professional relations and clinical practice, we hoped to uncover serious moral engagement on several key issues in the policies of all parties, and perhaps some indication of how the complex responsibilities of health care delivery should be shared. Our findings, however, show that the ethics policies of all three types of organisations tend to be narrowly focused. With important exceptions, physician codes of ethics confine themselves to patient/physician interactions and do not directly address the larger network of interactions and responsibilities that managed care presents. For their part, health plans formally endorse few traditional medical care norms in their policies and they offer only occasional recognition of how their policies might affect physicians' interactions with patients and society. In regard to social obligations, no group displays the attention one might hope to ethical aspects of resource allocation or care of vulnerable populations.

Even given the acknowledged limitations of collecting ethics materials to ascertain ethical action, the issues of health care ethics that we examined-professional obligations toward patients, resource allocation, and caring for vulnerable persons-are so pivotal that our findings might be surprising to many. For example, because health care is now largely mediated through health plans, and since there is wide and vocal public concern for the way efficiency measures and profit motives might compromise patient care, one might expect that clear written expressions by plans that they affirm physicians' professional obligations to act with beneficence and as patient advocates would be both prudent and socially desirable. Similarly, statements of recognition by physicians' professional associations that group practices and health plans have a legitimate role to play in the stewardship of shared health care resources might improve the health care climate.

This study demonstrates that a great deal of collaborative work is needed to place physicians and health plans on the same page ethically. If we are to build a health care system with strong ethical foundations, then individual physicians, group practices, and health plans will need to develop a greater sense of common aims and responsibilities, and a mutual recognition that each party has an important role to play in establishing and sustaining integrated sets of ethical standards that are necessary for the health care system to work. Shared and complementary ethical standards that are mutually affirmed by physicians and plans, and understood by the public, are not the only elements important to health care, but they are necessary. This study suggests that a collaborative dialogue to establish what these standards should be is overdue.

\section{AUTHORS' NOTE}

The views and opinions contained in this article are those of the authors and should in no way be construed as representing official policies of the American Medical Association.

\section{ACKNOWLEDGEMENT}

The authors thank the Sheps Center For Health Services Research for providing resources and assistance throughout our project and in particular; our project administrator Anne Jackman, MA; Gail Henderson, PhD, who provided helpful methodological comments for this paper; the expert panel that created the Health Ethics Taxonomy used in this research, and the Oversight Body of the Ethical Force Program for their helpful comments on earlier reports based on this research.

\author{
Authors' affiliations \\ N D Berkman, Research Triangle Institute, Research Triangle Park, NC, \\ USA \\ M K Wynia, The Institute for Ethics at the American Medical Association, \\ Chicago, IL, USA \\ L R Churchill, Center for Clinical and Research Ethics, Vanderbilt \\ University, Nashville, TN, USA
}




\section{REFERENCES}

1 Baker R, Caplan A, Emanuel L, et al. The American medical ethics revolution: how the AMA's code of ethics has transformed physicians' relationships to patients, professionals, and society. Baltimore, MD: Johns Hopkins University Press, 1999.

2 Jonsen A. A short history of medical ethics. New York, NY: Oxford University Press, 2000.

3 Zhang D, Cheng Z. Medicine is a humane art: the basic principles of professional ethics in Chinese medicine. Hastings Cent Rep 2000;30(suppl):8-12S

4 Orentlicher $\mathrm{D}$. The influence of professional organisations on physician behavior. Alb L Rev 1994;57:583-605.

5 Angell M. The doctor as double agent. Kennedy Inst Ethics J 1993;3:279-86.

6 Kassirrer J. Managing care: should we adopt a new ethic? N Engl J Med 1998;339:397-8

7 Mechanic D, Schlesinger M. The impact of managed care on patients' trust in medical care and their physicians. JAMA 1996;275:1693-7.

8 Wynia M, Latham S, Kao A, et al. Medical professionalism in society. NEngl J Med 1999;341:1612-16.

9 Levinsky N. Physician ethics in managed care settings. Am J Managed Care 1995; 1:77-80.

10 Clancy C, Brody H. Managed care: Jekyll or Hyde? JAMA 1995;273:338-9

11 Shortell S, Waters T, Clarke K, et al. Physicians as double agents: maintaining trust in an era of multiple accountabilities. JAMA 1998;280:1102-8.

12 Mechanic D. Managed care and the imperative for a new professional ethic. Health Aff 2000;19:100-11.

13 Gold M, Hurley R, Lake T, et al. A national survey of the arrangements managed-care plans make with physicians. N Engl J Med 1995; 333:1678-83.

14 American Medical Association. Socioeconomic characteristics of medical practice 1996. Chicago, IL: American Medical Association, 1996.

15 Emanuel L. Professional standards in health care: calling all parties to account. Health Aff 1997; 16:52-4.

16 Wynia M. Performance measures for ethics quality. Eff Clin Pract $1999 ; 2: 294-8$

17 Wynia M, Coughlin S, Alpert S, et al. Shared expectations for protection of identifiable health care information. J Gen Intern Med 2001;16:100-11.

18 Joint Commission on Accreditation of Healthcare Organisations. Ethical issues and patient rights: across the continuum of care. Oakbrook Terrace, IL: Joint Commission on Accreditation of Healthcare Organisations, 1998.

19 Woodstock Theological Center. Ethical issues in managed health care organisations. Washington DC: Georgetown University Press, 1999.

20 Rodwin M. Conflicts in managed care. N Engl J Med 1995;332:604-7.

21 Mariner W. Business ethics versus medical ethics. Am J Law Med Ethics 1995:23:236-46.

22 Buckovich S, Rippen H, Rozen M. Driving towards guiding principles: a goal for privacy, confidentiality, and security of health information. J Am Med Inform Assoc 1999;6:122-33.

23 Wynia M, for the Ethical Force Program Oversight Body. Protecting identifiable health care informational privacy: a consensus report on eight content areas for performance measure development. Chicago IL: The Institute for Ethics at the American Medical Association, 2001.
24 Berkman N Churchill L, Lux L, et al. A pilot study analysis of codes of professional/medical ethics, Research Triangle Institute Report no 7154-000. Research Triangle Institute, 1998.

25 Miles M, Huberman A. Qualitative data analysis: an expanded sourcebook [2nd ed]. Thousand Oaks, CA: Sage, 1994.

26 Berkman N, Thorp J, Hartmann K. Management of preterm labor: evidence report no 3, United States Agency for Healthcare Research and Quality Publication no 01-E021. 2000.

27 Churchill L. Beneficence. In: Encyclopedia of bioethics, vol 1 [rev ed]. New York: Simon and Schuster, 1995:243-7.

28 Beauchamp T, Childress J. Principles of biomedical ethics [4th ed]. New York: Oxford University Press, 1994.

29 Daniels N. Just health care. New York: Cambridge University Press, 1984.

30 Saltman R, Ferrousier-Davis O. The concept of stewardship in health policy. Bull World Health Organ 2000;78:732-9.

31 Minogue B. The two fundamental duties of the physician. Acad Med 2000;75:431-42.

32 Thomasma D. Stewardship of the aged: meeting the ethical challenges of ageism. In honor of Joseph Fletcher. Camb Q Healthc Ethics 1999;8:148-59.

33 Larkin G, Weber J, Moskop J. Resource utilization in the emergency department: the duty of stewardship. J Emerg Med 1998;16:499-503.

34 Sabin J. General hospital psychiatry and the ethics of managed care. Gen Hosp Psych 1995; 17:293-8.

35 Pellegrino E. Altruism, self interest, and medical ethics. JAMA 1987;258:1939-40.

36 Sullivan W. What is left of professionalism after managed care? Hastings Cent Rep 1999;29:7-13

37 Lundberg G, Bodine L. Fifty hours for the poor. JAMA 1987;258:3157.

38 Anon. Update for patient advocacy: principles of medical ethics [editorial]. Am Med News 2001 Aug 13:32.

39 Daniels N. Four unsolved rationing problems: a challenge. Hastings Cent Rep 1994;24:27-9.

40 Emanuel $\mathrm{E}$. Justice and managed care: four principles for the just allocation of health care resources. Hastings Cent Rep 2000;30:8-16.

41 American Medical Association. The code of medical ethics: current opinions. Chicago, IL: American Medical Association, 2000, opinion 2.03: allocation of limited resources.

42 Eddy D. What care is "essential"? What services are "basic"? JAMA 1991;265:782-8

43 Eisenberg J. Doctors' decisions and the cost of medical care. Ann Arbor, MI: Health Administration Press, 1986.

44 Callahan D. What kind of life? New York: Simon and Schuster, 1990.

45 Churchill L. Self interest and universal health care. Cambridge, MA: Harvard University Press, 1994

46 Fein R. Medical care. Medical cost. Cambridge, MA: Harvard University Press, 1986.

47 Council on Ethical and Judicial Affairs of the American Medical Association Caring for the poor. JAMA 1993;269:2533-7.

48 American Medical Association. Code of medical ethics: current opinions 1998-1999. Chicago, IL: American Medical Association, 1998.

49 The Ethical Force Program. www.ama-assn.org/e-force (accessed 21 Feb 2002).

50 Wynia M. Professionalism and professional associations in modern medicine. Audio-digest Family Practice, 1999;47 (audiotape). 